This is an Accepted Manuscript of an article published by Taylor \& Francis in Journal of Mental Health on 27/07/16, available online: https://www.tandfonline.com/doi/full/10.1080/09638237.2016.1207232 
Development of a global scale for teamwork

\title{
Validation of a global scale to assess the quality of interprofessional teamwork in mental health settings
}

\author{
Authors: \\ Ryoko Tomizawa ${ }^{a b} \quad$ rtomi@ncnp.go.jp \\ Mayumi Yamano ${ }^{c} \quad$ anchibi12@yahoo.co.jp \\ Mitue Osako $^{a} \quad$ m-osako@ncnp.go.jp \\ Naotugu Hirabayashi ${ }^{a} \quad$ hirabaya@ncnp.go.jp \\ Nobuo Oshima ${ }^{b} \quad$ oshima@tmu.ac.jp \\ Masahiro Sigeta $^{\mathrm{b}} \quad$ sigeta@tmu.ac.jp \\ Scott Reeves $^{\mathrm{d}} \quad$ s.reeves@ $@$ sgul.kingston.ac.uk
}

\section{Affiliations}

${ }^{a}$ National Center of Neurology and Psychiatry, 4-1-1 Ogawahigashi, Kodaira, Tokyo 187-8551, Japan

${ }^{\mathrm{b}}$ Graduate School, Tokyo Metropolitan University, 7-2-10, Higashioku, Arakawa, Tokyo 1168551, Japan

'National Hospital organization, Tokyo Medical Center, 2-5-1 Higashigaoka, Meguro, Tokyo 152-8902, Japan 
Development of a global scale for teamwork

${ }^{\mathrm{d} K i n g s t o n}$ University \& St George's, University of London, Kenry House, Kingston Hill

Campus, Kingston upon Thames, KT2 7LB, UK

\section{Corresponding author}

Ryoko Tomizawa

National Center of Neurology and Psychiatry, 4-1-1 Ogawahigashi, Kodaira, Tokyo 187-8551,

Japan

rtomi@ncnp.go.jp

+81 423-341-2711 (Japan)

Declaration of interest: This study was supported by an Intramural Research Grant (23-4) for

Neurological and Psychiatric Disorders from the National Center of Neurology and Psychiatry, Japan.

Acknowledgments: The authors acknowledge Amin Azzan and Midori Nakajima at the

University of California, San Francisco and Norio Watanabe at the National Center of

Neurology and Psychiatry for consultation regarding participant recruitment and analysis. 
Development of a global scale for teamwork

\title{
Validation of a global scale to assess the quality of interprofessional teamwork in mental health settings
}

\begin{abstract}
Background: Few scales currently exist to assess the quality of interprofessional teamwork through team members' perceptions of working together in mental health settings.
\end{abstract}

Aims: The purpose of this study was to revise and validate an interprofessional scale to assess the quality of teamwork in inpatient psychiatric units and to use it multi-nationally.

Methods: A literature review was undertaken to identify evaluative teamwork tools and develop an additional 12 items to ensure a broad global focus. Focus group discussions considered adaptation to different care systems using subjective judgements from 11 participants in a pretest of items. Data quality, construct validity, reproducibility, and internal consistency were investigated in the survey using an international, comparative design.

Results: Exploratory factor analysis yielded five factors with 21 items: 'patient/community centred care', 'collaborative communication', 'interprofessional conflict', 'role clarification', and 'environment'. High overall internal consistency, reproducibility, adequate face validity, and reasonable construct validity were shown in both countries.

Conclusions: The revised Collaborative Practice Assessment Tool (CPAT) is a valid measure to assess the quality of interprofessional teamwork in psychiatry and identifies the best strategies 
Development of a global scale for teamwork

to improve team performance. Furthermore, the revised scale will generate more rigorous evidence for collaborative practice in psychiatry internationally.

Conflict of interest: None.

Keywords: interprofessional collaboration, teamwork, psychiatry, quantitative evaluation, cross-cultural comparisons 
Development of a global scale for teamwork

\section{Introduction}

Interprofessional collaborative practice is considered by policymakers, health service managers, and practitioners as a possible strategy to strengthen the health workforce internationally (WHO, 2010). Interprofessional teamwork, which is one type of interprofessional collaborative practice, is defined as a type of work that involves different health and/or social professions that share a team identity and work closely together in an integrated and interdependent manner to solve problems and deliver services (Reeves et al., 2010). This type of intervention is also regarded as the key to improve the quality of client care, enhance client safety, and reduce workload that causes burnout among healthcare professionals (Canadian Health Services Research Foundation, 2006). While such findings are encouraging, interprofessional practice can generate a range of problems, such as power imbalances between professions, poor communication patterns, and professional conflicts (WHO, 2010; Zwarenstein et al., 2009). In order to reflect on team performance and identify the best strategies as a team, evaluation is necessary as a critical component of an interprofessional process (CIHC, 2012). In particular, through team members' perceptions of working together, the quality of team performance can be diagnostically assessed, because from an outside view, it may seem that a team is functioning well, but the perceptions of the team members may be that the team is not effective (Schroder et al., 2011). In other words, the overall quality of team performance is 
Development of a global scale for teamwork

enhanced, as the results of individual perceptions could be analysed as a team. However, few scales currently exist to estimate the quality of interprofessional teamwork in mental health settings through team members' perceptions of working together.

This study aimed to develop and validate a scale to diagnostically assess the quality of interprofessional teamwork in inpatient units in mental health settings and to use it multinationally. This new scale will help team members recognize their current strengths and weaknesses and identify the best strategies to improve team practice across cultural differences. Therefore, interprofessional teamwork will be practiced with greater satisfaction of professionals as well as benefit the clients. An international comparative approach was undertaken to initially investigate the utility of the scale in Japan and the United States (U.S.).

\section{Methods}

Six steps were undertaken for the development of the English and Japanese versions of the revised Collaborative Practice Assessment Tool (CPAT; Figure 1) (Schroder et al., 2011).

\section{INSERT FIGURE 1 ABOUT HERE}

\section{Literature review and tool selection}

The Canadian Interprofessional Health Collaborative (CIHC) report of interprofessional quantitative tools was consulted (CIHC, 2012), along with a search of Medline, CINAHL, and PSYCH INFO from April 2010 to June 2013 that was undertaken to retrieve tools not included 
Development of a global scale for teamwork

in the report using the same search terms. In order to extract scales available for assessment of the quality of interprofessional teamwork, scales developed for students in interprofessional education, scales used in specific fields or for specific occupations except mental health, and scales not validated psychometrically were excluded. In addition, two selection criteria were chosen: scales for assessing team members' perceptions and scales for which items can be classified under three categories based on the structure-process-outcome model (Donabedian, 1988).

The structure-process-outcome model was included as it is well known in the assessment and monitoring of quality of medical care in the health care system, with a three-part approach to quality assessment (Donabedian, 1988). Within this model, structure refers to staffing, hours of operation, provider workloads, and availability of evidence-based practices; process is the extent to which evidence-based practices are implemented in terms of frequency and timing; and outcome denotes the effects of care on the health status of patients including salutary changes of the patients' behaviour and satisfaction with care (Donabedian, 1988).

Based on this process, 136 assessment tools were retrieved for review. Of these, five scales were initially selected having met both selection and exclusion criteria and 131 were excluded. After the assessment of each scale, the CPAT was selected because it had more potential for practical explanation of the quality of interprofessional teamwork in mental health settings. 
Development of a global scale for teamwork

This scale was designed specifically in Canada to measure healthcare team members'

perceptions of working collaboratively, covering the full range of interprofessional teamwork. It comprises 56 items across nine domains such as mission, general relationships, team leadership, general role responsibility, communication, decision making and conflict management, community linkages, and patient involvement (Schroder et al., 2011). Moreover, the CPAT was developed for use in diverse fields including mental health. However, the CPAT was not useful to assess the quality of team performance in inpatient units in mental health settings multinationally, because most of the items are biased toward the process part of the structure-processoutcome model, do not express the characteristics of clients with severe mental illness, and do not evaluate multi-cultural differences. Thus, a revision of the CPAT was launched (with permission from the developers) to comprehensively evaluate the quality of interprofessional teamwork in mental health teams multi-nationally.

\section{Additional items}

The lead author (RT) reviewed and selected items to broaden the focus of the CPAT by comprehensively assessment key elements of interprofessional teamwork from worldwide policy documents and interprofessional guidelines (CIHC, 2010; Ministry of Health, Labour and Welfare, 2011; Interprofessional Education Collaborative [IPEC] Expert Panel, 2011; WHO, 2010) which could be incorporated into the structure-process-outcome model. After the co- 
Development of a global scale for teamwork

author's (SR) agreement, twelve items were finally added, for example: team members use respectful language during any interprofessional conflict, our organization has enough shared space (meeting rooms, break rooms, staff rooms, etc.) to work together effectively as a team, and team members recognize each other's strengths and limitations in terms of skills, knowledge, and abilities. Moreover, five items were revised to strengthen its relevance for clients with severe mental illness in inpatient units. Finally, the initial 68-item English version 1.0 was developed.

\section{Translation into Japanese}

The English version 1.0 was translated into Japanese in accordance with guidelines for translating and adapting psychometric scales (Wild et al., 2005). First, two Japanese practitioners with English proficiency and sufficient psychiatry experience independently translated the scale into Japanese. Second, the two forward translations were reconciled into a single forward translation by a practitioner fully experienced in interprofessional teams in psychiatry. This forward translation was then revised by the lead author (RT), reconciliation translator, and two psychiatry practitioners to strengthen the conceptual equivalence, avoid ambiguity, and arrive at more practical descriptions. Furthermore, two professional translators, a native English speaker and a native Japanese speaker proficient in both Japanese and English, performed the backward translation from Japanese into English. Neither of them knew the 
Development of a global scale for teamwork

original English version CPAT. The native English speaking co-author (SR) then ascertained whether the backward translation preserved the original English version content. Based on a review of the backward translation, the forward translation was revised to ensure conceptual equivalence, and the initial Japanese version 1.0 was accepted.

Pre-testing of items

In a pre-test of items, face validity was evaluated through an online or written survey in Japan and the U.S. (Japanese or English version 1.0) (Mokkink et al., 2010). We obtained subjective judgements about the clarity and comprehensiveness of the items, and the items' relevance to the quality of interprofessional teamwork to be assessed in psychiatry.

\section{Focus group discussion}

A focus group was conducted with four professionals (a nurse, psychologist, occupational therapist, and social worker) in Japan (Mokkink et al., 2010) to discuss the subjective judgements from the pre-test of items and consider adaptations from US to Japanese care systems and cultures. The focus group also asked participants to revise any confusing Japanese wording generated from the translation process.

Survey

Participants. A survey was conducted for professionals (working in psychiatric inpatient units of two hospitals in the U.S. and in four forensic psychiatric units in Japan), using version 
Development of a global scale for teamwork

1.1, from November 2013 to February 2014. Although general psychiatric and forensic psychiatric inpatient units differ, forensic psychiatric units were selected in Japan because interprofessional teams from diverse professions are systematically assembled only in these units to provide intensive inpatient treatment and rehabilitation for mentally ill offenders (Weisstub \& Carney, 2006). To examine reproducibility, the CPAT Japanese version 1.1 was distributed two weeks after the first administration in a forensic inpatient unit in Japan (Mokkink et al., 2010; Terwee et al., 2007). Participants completed the revised CPAT version 1.1 online or on paper using a 7-point Likert scale ranging from 1 (strongly disagree) to 7 (strongly agree). Furthermore, a Visual Analogue Scale (VAS) was used to assess the extent to which professionals were satisfied with their team and to judge whether the quality of interprofessional teamwork was correlated with team members' satisfaction. In addition, respondents were asked to indicate their gender, age, occupation, years of occupational experience, and years of experience in the unit.

Sample size was determined based on recommendations by Terwee et al. that at least 50 participants are required to investigate construct validity, test-retest reliability, and ceiling/floor effects, and that approximately 100 participants are necessary for internal consistency analysis (Terwee et al., 2007).

Analysis. Statistical analyses were conducted using IBM SPSS Statistics for Windows, version 
Development of a global scale for teamwork

22 (IBM Corp., Armonk, NY). Statistical significance was set at $\mathrm{p}<.05$ (two-tailed test).

Data quality. Floor or ceiling effects were considered if the lowest or highest possible score was chosen by more than $15 \%$ of respondents (Terwee et al., 2007).

Construct validity. Exploratory factor analysis (EFA) using the principal components method and promax rotation was conducted for version 1.1. To capture core items across cultures, we considered whether each item had adequate factor loadings across the two versions.

The correlation of the scores of version 1.2 with the VAS was calculated according to an a priori hypothesis that interprofessional teamwork would be moderately to strongly correlated with professionals' satisfaction with interprofessional teams (Mokkink et al., 2010; Terwee et al., 2007). This hypothesis was developed based on previous research findings that team members experience socio-emotional benefits (e.g. improved job satisfaction, greater role clarity, and enhanced well-being) (Mickan, 2005). Spearman's correlation coefficients were used in this analysis $(<.3, .3$ to .6 , and $>.6$ were considered low, moderate, and high, respectively) (Andresen, 2000).

Reproducibility. Reproducibility concerns the degree to which repeated measurements of stable persons provide similar answers (de Vet et al., 2010; Mokkink et al., 2010; Terwee et al., 2007). This includes reliability and agreement.

Agreement was represented by the standard error of measurement (SEM). SEM equals the 
Development of a global scale for teamwork

square root of the error variance of an ANOVA. Furthermore, the SEM can be converted into the minimal detectable change $(\mathrm{MDC})(\mathrm{MDC}=1.96 \times \sqrt{2} \times \mathrm{SEM})$, which reflects the smallest score change that can be interpreted as real change and not a measurement error at $\mathrm{p}<.05$ (de Vet et al., 2010; Mokkink et al., 2010; Terwee et al., 2007).

Reliability was assessed using an intraclass correlation coefficient (ICC) for the total score in a two-way random effects model and weighted kappa for each item. These indicators were compared with recommended standards for ICC (>.70) and kappa (good: >.61; moderate: .41 to .60; slight: .21 to .40; and poor: <.20) (Fayers \& Machin, 2007).

Internal consistency. Internal consistency was assessed using Cronbach's alpha coefficient (values between .70 and .95 indicate good internal consistency) (Mokkink et al., 2010; Terwee et al., 2007).

Ethical considerations. These studies were approved by the ethical committees of the University of California, San Francisco; the National Center of Neurology and Psychiatry in Japan, and the Tokyo Metropolitan University in Japan. All respondents gave their informed consent before completing the survey, and participants in the U.S. were paid $\$ 10$ for each survey.

\section{Results}

Pre-test of items 
Development of a global scale for teamwork

After translation into Japanese, subjective judgements were obtained in the pre-test of items from 11 participants: five psychiatrists and an interprofessional expert in the U.S., and five psychiatry professionals (a psychiatrist, nurse, psychologist, occupational therapist, and social worker) in Japan.

\section{Focus group discussions}

Using the subjective judgements of all 11 participants, the focus group discussions were conducted with four different professionals (a nurse, psychologist, occupational therapist, and social worker) who did not complete the pre-test. Consensus between participants was achieved that the modified CPAT was accurately adapted for inpatient psychiatric units under both care systems with the modification that two items were discarded and six were amended.

Furthermore, the revised six items were translated into English by the lead author (RT) to ensure conceptual equivalence. After review by the native English speaking co-author (SR), the 66item English and Japanese versions 1.1 were completed.

Survey

Version 1.1 was administered to assess construct validity, reproducibility, and internal consistency reliability in the U.S. and Japan. Eighty-six U.S. and 194 Japanese respondents participated. However, nine English and six Japanese respondents were excluded because of unreliable responses (e.g. same response choice for all items, five or more missing data points), 
Development of a global scale for teamwork

leaving 77 U.S. and 188 Japanese respondents. In Japan, the 167 respondents without missing data were included in the subsequent analysis, whereas in the U.S., the 77 respondents with four or fewer missing data points were included to maintain adequate sample numbers (Mokkink et al., 2010; Terwee et al., 2007). Forty-three respondents had valid data for both administrations to examine reproducibility in Japan.

\section{Characteristics of respondents}

Table 1 shows respondents' sociodemographic characteristics. A comparison between respondents in the U.S. and Japan found no significant differences in gender or occupational experience; however, there were significant differences in age, occupation, and years of experience in the unit.

\section{INSERT TABLE 1 ABOUT HERE}

\section{Data quality}

Initially, three items with ceiling effects higher than $15 \%$ in both the English and Japanese versions were excluded. All items had fewer than three missing values as described above. The proportion of missing values ranged from $.53 \%$ to $1.06 \%$ in Japan and was $1.3 \%$ in the U.S. Two items (items 4 and 18) had ceiling effects in Japan, and 17 items (items 2-16, 18, and 20) had ceiling effects in the U.S. (Table 2). No floor effects were identified. 
Development of a global scale for teamwork

\section{INSERT TABLE 2 ABOUT HERE}

\section{Construct validity}

Initially, 20 items with low factor loadings in either or both versions were excluded. Five factors based on the criteria of eigenvalues greater than 1.00 were finally adopted as the best factor structure in Table 3. Version 1.2 was completed with 21 items from five factors:

'patient/community centred care', 'collaborative communication', 'interprofessional conflict', 'role clarification', and 'environment'. Furthermore, version 1.2 included the four original items, two revised items, and 15 items from the CPAT. Unexpectedly, item 21 had factor loadings greater than .40 for two factors. However, item 21 was classified on factor 5 in accordance with the cluster meaning. The English version of the revised CPAT explained $72.97 \%$ of the variance and the Japanese version explained $56.57 \%$.

Factor 1 (six items) included effectively addressing patients' concerns through regular team meetings and discussion with patients, family members, and community service agencies, and whether the interprofessional team had a process to optimize the coordination of patient care with community staff.

Factor 2 (four items) included attitudes and behaviours in communicating with other professionals, and whether the best treatment was determined through respectful and effective communication. 
Development of a global scale for teamwork

Factor 3 (four items) was typified by the recognition of potential or current conflict among team members. This concept might be used to identify the extent to which conflicts occur in interprofessional teams.

Factor 4 (four items) covered the recognition of each other's roles and responsibilities in interprofessional teams and the use of effective discussion and interaction based on one another's knowledge, skills, and attitudes. It also reflects whether professionals' roles are flexibly decided based on the context of their clinical work, and whether patient care plans and treatment goals incorporate best practice guidelines from multiple professions.

Factor 5 (3 items) addresses the environment of interprofessional teams, such as building design, time, and facilities, which can enhance or detract from collaborative practice, and the assessment of the extent to which the environment can improve functioning in interprofessional teams.

\section{INSERT TABLE 3 ABOUT HERE}

The hypothesis regarding correlations between the revised CPAT version 1.2 and the VAS was confirmed ( $\mathrm{p}<.01,2$-tailed). The version 1.2 total score was strongly and significantly correlated with the VAS in the U.S. (.77) and Japan (.62). 
Development of a global scale for teamwork

In terms of agreement, the SEM for each item was between .52 and 1.19. The MDC for each item was between 1.45 and 3.31, and the MDC percentage for each item was between 20.69 and 47.29 (exceeding 20\%).

The ICC for the total score was $.83(95 \%$ confidence interval $[\mathrm{CI}]=.70$ to .90$)$, exceeding the recommended standard of .70. Weighted kappas for each item were also examined. Six items had weighted kappas greater than .61, indicating good reliability; eight had kappas from .41 to .60 , showing moderate reliability; and the other six (items $1,3,13,14,16$, and 18) had weighted kappas of .40 or less, indicating slight or poor reliability. Weighted kappas were particularly low $(.06, .20, .12)$ for three items (items 1,3 , and 16 , respectively).

\section{Internal consistency}

In the U.S., Cronbach's alpha coefficients for each of the five factors were $.91, .84, .83, .85$, and .75 , and none of the factors had Cronbach's alpha coefficients of .70 or less. Cronbach's alpha coefficients were $.76, .75, .67, .71$, and .69 in Japan. Coefficients smaller than .70 were found for two factors.

\section{Discussion}

This study developed the revised CPAT version 1.2 for assessing the quality of interprofessional teamwork in inpatient units in psychiatry with high overall internal consistency, reliability and reproducibility, adequate face validity, and reasonable construct 
Development of a global scale for teamwork

validity in both countries. These results indicate that it is a useful scale to use internationally with practical relevance to the quality of interprofessional teamwork in mental health settings, especially inpatient units.

How to use the revised CPAT in clinical settings

Version 1.2 included items that were classified under two categories, such as structure and process, based on the structure-process-outcome model. However, no items were categorised under outcome based on this model. On the other hand, the revised CPAT version 1.2 was strongly and significantly correlated with professionals' satisfaction with interprofessional teams. These results indicate that version 1.2 can be used to measure the quality of interprofessional teamwork, especially the structure and process parts of quality assessment, and that the total score of version 1.2 expresses the outcome aspect of quality assessment, such as professionals' satisfaction. In other words, the use of this scale could help team members systematically identify team issues in detail and analyse the results as a team to identify the best strategies based on team members' perceptions. This scale could also help professionals continue to work without burnout, because better satisfaction through team reflection would motivate professionals toward better practice. Therefore, this scale is useful when interprofessional teams are not functioning well, or when team performance seems to be functioning well but without the clients' or professionals' satisfaction. 
Development of a global scale for teamwork

Furthermore, this scale was revised to meet characteristics of clients with severe mental illness in inpatient units in psychiatry. Therefore, the use of this scale for assessing quality of interprofessional teamwork would make it possible to address clients' satisfaction with team performance as well as professionals' satisfaction.

\section{Scale originality}

As this scale is meant to be used multi-nationally, the items about interprofessional conflict management and leadership were deleted because they did not combine into a cluster of meaning in either country. In other words, methods of solving interprofessional conflict might be dependent upon the culture and context of clinical work because collaborative practice works best when it is organized around the population's needs and the delivery of local healthcare (WHO, 2010). This scale is expected to be used for assessing the quality of interprofessional teamwork and for providing information about what team members should improve in their team.

\section{Limitations}

There are a number of potential limitations related to this study. First, generalisation of the findings should be undertaken with caution because participants were selected from a small number of hospitals. Therefore, biased participants might have caused the ceiling effects. Future 
Development of a global scale for teamwork

studies conducted with professionals from various hospitals are required to determine whether ceiling effects exist and whether the scale can be generalised. Second, test-retest reliability was evaluated only in Japan using the smaller sample size. Further investigations of test-retest reliability in both countries with adequate sample sizes are necessary. Finally, this scale was developed as a global measure of the quality of interprofessional teamwork across cultures. However, this study investigated reliability and validity only in the U.S. and Japan. To evaluate the reliability and validity of the revised CPAT internationally, research in other countries is suggested.

\section{Conclusions}

This study developed a global scale to generate new insights in two areas. First, the revised scale more robustly describes the quality of interprofessional teams in mental health and identifies the best strategies to improve team performance. Second, the revised scale helps to generate more rigorous evidence for collaborative practice in mental health settings internationally. To further evaluate the reliability and validity of the revised CPAT as a global scale, future research is required in other countries with an adequate number of participants from diverse hospitals. 
Development of a global scale for teamwork

\section{References}

Andresen E.M. (2000). Criteria for assessing the tools of disability outcomes research. Archives of Physical Medicine and Rehabilitation, 12(2), 15-20.

Canadian Health Services Research Foundation (2006). Teamwork in health care: Promoting effective teamwork in healthcare in Canada. Ottawa: Canadian Health Services Research Foundation.

Canadian Interprofessional Health Collaborative (2010). A National Interprofessional Competency Framework. Available at http://www.cihc.ca/files/CIHC_IPCompetencies_Feb1210.pdf

Canadian Interprofessional Health Collaborative (2012). An inventory of quantitative tools measuring interprofessional education and collaborative practice outcomes. Available at http://www.chd.ubc.ca/files/file/instructor-resources/CIHC_tools_report_ Aug26\%202012.pdf

de Vet H.C., Terwee C.B. (2010). The minimal detectable change should not replace the minimal important difference. Journal of Clinical Epidemiology, 63(7), 804-805.

Donabedian A. (1988). The quality of care: How can it be assessed? JAMA, 260(12), 17431748.

Fayers P.M., Machin D. (2007). Quality of Life: The Assessment, Analysis and Interpretation of 
Development of a global scale for teamwork

Patient-Reported Outcomes. 2nd ed. Available at

http://onlinelibrary.wiley.com/doi/10.1002/9780470024522.ch1/summary

IPEC (Interprofessional Education Collaborative) Expert Panel (2011). Core competencies for interprofessional collaborative practice: Report of an expert panel. Washington, D.C.: Interprofessional Education Collaborative. Available at http://www.aacn.nche.edu/education-resources/ipecreport.pdf

Mickan S.M. (2005). Evaluating the effectiveness of health care teams. Australian Health Review, 29(2), 211-217.

Ministry of Health, Labour and Welfare (2011). Basic concepts and case studies for promoting teamwork. Available at http://www.mhlw.go.jp/stf/shingi/2r9852000001ehf7.html

Mokkink L.B., Terwee C.B., Patrick D.L., Alonso J., Stratford P.W., Knol D.L., Bouter L.M., de Vet H.C. (2010). COSMIN checklist manual. Institution for Health and Care Research. Available at http://www.cosmin.nl/images/upload/files/COSMIN\%20checklist\%20manual\%20v9.pdf

Reeves S., Lewin S., Espin S., Zwarenstein M. (2010). Interprofessional teamwork for health and social care. UK: John Wiley \& Sons.

Schroder C., Medves J., Paterson M., Bymes V., Chapman C., O’Riordan A., Pichora D., Kelly C. (2011). Development and pilot testing of the collaborative practice assessment tool. 
Development of a global scale for teamwork

Journal of Interprofessional Care, 25, 189-195.

Terwee C.B., Bot S.D., de Boer M.R., van der Windt D.A., Knol D.L., Dekker J., Bouter L.M., de Vet H.C. (2007). Quality criteria were proposed for measurement properties of health status questionnaires. Journal of Clinical Epidemiology, 60, 34-42.

Weisstub D.N., Carney T. (2006). Forensic mental health law reform in Japan: From criminal warehousing to broad-spectrum specialist services? International Journal of Law and Psychiatry, 29, 86-100.

Wild D., Grove A., Martin M., Eremenco S., McElroy S., Verjee-Lorenz A., Erikson P. (2005). Principles of good practice for the translation and cultural adaptation process for patientreported outcomes (PRO) measures: Report of the ISPOR task force for translation and cultural adaptation. Value Health, 8(2), 94-104.

World Health Organization (2010). Framework for action on interprofessional education \& collaborative practice. Geneva, Switzerland: Author.

Zwarenstein M., Goldman J., Reeves, S. (2009). Interprofessional collaboration: effect of practice-based interventions on professional practice and healthcare outcomes. Cochrane Database of Systematic Reviews, 3 (CD000072). 
Development of a global scale for teamwork

Table 1

Characteristics of respondents for version 1.1

\begin{tabular}{|c|c|c|c|c|c|c|}
\hline & & \multicolumn{2}{|c|}{ USA $(N=77)$} & \multicolumn{2}{|c|}{ Japan $(\mathrm{N}=167)$} & \multirow{2}{*}{$p$} \\
\hline & & $\mathrm{N}$ & $\%$ & $\mathrm{~N}$ & $\%$ & \\
\hline \multirow[t]{3}{*}{ Gender } & Male & 25 & 32.5 & 74 & 44.3 & \multirow{3}{*}{.126} \\
\hline & Female & 49 & 63.6 & 83 & 49.7 & \\
\hline & Unknown & 3 & 3.9 & 10 & 6.0 & \\
\hline \multirow[t]{6}{*}{ Age } & 20-29 & 9 & 11.7 & 15 & 9.0 & \multirow{6}{*}{$.014^{*}$} \\
\hline & 30-39 & 19 & 24.7 & 54 & 32.3 & \\
\hline & $40-49$ & 17 & 22.1 & 54 & 32.3 & \\
\hline & $50-59$ & 26 & 33.8 & 33 & 19.8 & \\
\hline & $\geq 60$ & 4 & 5.2 & 1 & .6 & \\
\hline & Unknown & 2 & 2.6 & 10 & 6.0 & \\
\hline \multirow[t]{8}{*}{ Occupation } & Psychiatrist & 17 & 22.1 & 10 & 6.0 & \multirow{8}{*}{$<.001^{*}$} \\
\hline & Nurse & 35 & 45.5 & 120 & 71.9 & \\
\hline & Psychologist & 2 & 2.6 & 9 & 5.4 & \\
\hline & Social worker & 7 & 9.1 & 8 & 4.8 & \\
\hline & Occupational therapist & 7 & 9.1 & 9 & 5.4 & \\
\hline & Pharmacist & 2 & 2.6 & 0 & 0 & \\
\hline & Rehabilitation therapist & 3 & 3.9 & 0 & 0 & \\
\hline & Unknown & 4 & 5.2 & 11 & 6.6 & \\
\hline \multirow[t]{2}{*}{ Years } & $\begin{array}{l}\text { Occupational experience } \\
\text { (mean } \pm \text { SD) }\end{array}$ & \multicolumn{2}{|c|}{$13.3 \pm 10.7$} & \multicolumn{2}{|c|}{$14.4 \pm 8.1$} & .421 \\
\hline & $\begin{array}{l}\text { Experiences in units } \\
\text { (mean } \pm \text { SD) }\end{array}$ & \multicolumn{2}{|c|}{$6.4 \pm 6.8$} & \multicolumn{2}{|c|}{$3.4 \pm 1.9$} & $.001^{*}$ \\
\hline
\end{tabular}

* significant difference between the U.S. and Japan $(p<.05)$

Chi-square tests were calculated for gender, age, and occupation data, and t-tests were calculated for years of experience data. 
Development of a global scale for teamwork

Table 2

Items with missing data and floor or ceiling effects

\begin{tabular}{|c|c|c|c|c|c|c|c|c|c|}
\hline & \multirow{3}{*}{ Items (response format and wording) } & \multicolumn{4}{|c|}{ USA $(\mathrm{N}=77)$} & \multicolumn{4}{|c|}{ Japan $(\mathrm{N}=188)$} \\
\hline & & \multicolumn{2}{|c|}{ Missing data } & \multirow{2}{*}{$\begin{array}{l}\text { Lowest } \\
(\%)\end{array}$} & \multirow{2}{*}{$\begin{array}{c}\text { Highest } \\
(\%)\end{array}$} & \multicolumn{2}{|c|}{ Missing data } & \multirow{2}{*}{$\begin{array}{c}\text { Lowest } \\
(\%)\end{array}$} & \multirow{2}{*}{$\begin{array}{c}\text { Highest } \\
(\%)\end{array}$} \\
\hline & & & $\%$ & & & & $\%$ & & \\
\hline 1 & $\begin{array}{l}\text { The patient's/client's family and supports are included in care planning, at the } \\
\text { patient's request. }\end{array}$ & 0 & 0 & 5.2 & 10.4 & 1 & .5 & 2.7 & 2.1 \\
\hline 2 & $\begin{array}{l}\text { Information relevant to health care planning is shared with the patient/client in } \\
\text { such a way that is understandable. }\end{array}$ & 0 & 0 & 7.8 & $20.8^{*}$ & 0 & 0 & 1.6 & 7.4 \\
\hline 3 & $\begin{array}{l}\text { Patients/clients concerns are addressed effectively through regular team } \\
\text { meetings and discussion. }\end{array}$ & 0 & 0 & 1.3 & $23.4^{*}$ & 0 & 0 & 0 & 6.4 \\
\hline 4 & $\begin{array}{l}\text { Our team has established partnerships with community organizations to } \\
\text { support better patient/client outcomes. }\end{array}$ & 1 & 1.3 & 0 & $51.3^{*}$ & 1 & .5 & 1.1 & $16.6^{*}$ \\
\hline 5 & $\begin{array}{l}\text { Our team has a process to optimize the coordination of patient/client care with } \\
\text { community service agencies. }\end{array}$ & 0 & 0 & 0 & $24.7^{*}$ & 0 & 0 & 0 & 5.9 \\
\hline 6 & Team members meet face-to-face with patients/clients cared for by the team. & 0 & 0 & 1.3 & $29.9^{*}$ & 0 & 0 & .5 & 5.9 \\
\hline 7 & $\begin{array}{l}\text { Our team's level of respect for each other enhances our ability to work } \\
\text { together. }\end{array}$ & 0 & 0 & 0 & $36.4^{*}$ & 0 & 0 & 0 & 7.4 \\
\hline 8 & $\begin{array}{l}\text { When team members disagree, all points of view are considered before } \\
\text { deciding on a solution. }\end{array}$ & 0 & 0 & 0 & $32.5^{\star}$ & 0 & 0 & 0 & 7.4 \\
\hline 9 & Team members use respectful language during any interprofessional conflict. & 0 & 0 & 2.6 & $35.1^{*}$ & 0 & 0 & .5 & 6.4 \\
\hline 10 & Team members care about one another's personal well-being. & 0 & 0 & 1.3 & $31.2^{\star}$ & 1 & .5 & 2.1 & 3.7 \\
\hline 11 & Disagreements among team members are ignored or avoided. & 0 & 0 & 0 & $46.8^{*}$ & 0 & 0 & 0 & 11.2 \\
\hline 12 & $\begin{array}{l}\text { In our team, there are problems that regularly need to be solved by someone } \\
\text { higher up. }\end{array}$ & 0 & 0 & 0 & $20.8^{\star}$ & 0 & 0 & 1.6 & 3.2 \\
\hline 13 & Our team leader is out of touch with team members' concerns and perceptions. & 1 & 1.3 & 1.3 & $28.9^{*}$ & 0 & 0 & .5 & 3.7 \\
\hline 14 & $\begin{array}{l}\text { Team members feel limited in the degree of autonomy in patient/client care } \\
\text { that they can assume. }\end{array}$ & 0 & 0 & 0 & $35.1^{*}$ & 1 & .5 & .5 & 4.2 \\
\hline 15 & $\begin{array}{l}\text { Team members recognize each other's strengths and limitations in skills, } \\
\text { knowledge, and abilities. }\end{array}$ & 0 & 0 & 1.3 & $19.5^{\star}$ & 0 & 0 & 0 & 3.2 \\
\hline 16 & $\begin{array}{l}\text { Team members acknowledge the aspects of care where members of my } \\
\text { profession have more skills and expertise. }\end{array}$ & 0 & 0 & 1.3 & $24.7^{\star}$ & 0 & 0 & .5 & 3.2 \\
\hline 17 & It is clear who is responsible for aspects of the patient/client care plan. & 1 & 1.3 & 7.9 & 5.3 & 0 & 0 & 4.8 & .5 \\
\hline 18 & $\begin{array}{l}\text { Patient/client care plans and treatment goals incorporate best practice } \\
\text { guidelines from multiple professions. }\end{array}$ & 1 & 1.3 & 5.2 & $26.0^{*}$ & 2 & 1.1 & 1.6 & $15.1^{*}$ \\
\hline 19 & Our team's mission and goals are supported by sufficient time. & 0 & 0 & 3.9 & 10.4 & 0 & 0 & 5.3 & 2.1 \\
\hline 20 & $\begin{array}{l}\text { Our organization has enough shared space (meeting rooms, break rooms, staff } \\
\text { rooms, etc.) to work together effectively as a team. }\end{array}$ & 0 & 0 & 3.9 & $18.2^{*}$ & 0 & 0 & 2.7 & 4.8 \\
\hline 21 & $\begin{array}{l}\text { There is support from the organization (affiliated departments, hospitals, etc.) } \\
\text { for teamwork. }\end{array}$ & 0 & 0 & 14.3 & 7.8 & 0 & 0 & .5 & 9.6 \\
\hline
\end{tabular}


Development of a global scale for teamwork

* Items with floor or ceiling effects (lowest or highest >15\%) 
Development of a global scale for teamwork

Table 3

Factors of the revised CPAT: item factors using the principal components method and promax rotation

\begin{tabular}{|c|c|c|c|c|c|c|c|c|c|c|c|c|c|c|}
\hline \multirow{2}{*}{ No } & \multicolumn{2}{|c|}{ USA $(\mathrm{N}=77)$} & \multicolumn{2}{|c|}{ Japan $(\mathrm{N}=167)$} & \multicolumn{2}{|c|}{ Factor 1} & \multicolumn{2}{|c|}{ Factor 2} & \multicolumn{2}{|c|}{ Factor 3} & \multicolumn{2}{|c|}{ Factor 4} & \multicolumn{2}{|c|}{ Factor 5} \\
\hline & $M$ & SD & M & SD & USA & Japan & USA & Japan & USA & Japan & USA & Japan & USA & Japan \\
\hline 1 & 5.79 & 1.29 & 5.43 & .87 & .74 & .76 & .28 & .00 & -.04 & .25 & .01 & -.17 & -.21 & -.07 \\
\hline 2 & 5.69 & 1.18 & 5.17 & 1.06 & .82 & .74 & -.14 & -.24 & -.01 & -.05 & .17 & .26 & -.04 & .01 \\
\hline 3 & 5.52 & 1.54 & 5.29 & .95 & .56 & .64 & .07 & -.01 & .00 & -.04 & .34 & .06 & -.00 & .07 \\
\hline 4 & 5.69 & 1.39 & 5.34 & .84 & .63 & .60 & .14 & .33 & -.11 & .03 & .23 & -.03 & -.06 & -.09 \\
\hline 5 & 5.70 & 1.25 & 5.17 & 1.06 & .96 & .56 & -.14 & .28 & .07 & -.07 & -.10 & .10 & -.02 & -.09 \\
\hline 6 & 6.32 & .85 & 5.56 & 1.16 & .59 & .50 & .15 & .08 & .11 & -.12 & .18 & -.07 & -.20 & .02 \\
\hline 7 & 6.16 & .99 & 5.26 & 1.04 & -.14 & .10 & .57 & .78 & .04 & -.25 & .37 & -.26 & .04 & .14 \\
\hline 8 & 5.34 & 1.38 & 4.84 & 1.05 & .06 & -.00 & .83 & .75 & -.02 & -.07 & .01 & .21 & .09 & -.04 \\
\hline 9 & 5.75 & 1.26 & 5.26 & .94 & .04 & -.02 & 1.02 & .60 & -.08 & .18 & -.17 & .21 & -.03 & .05 \\
\hline 10 & 5.71 & 1.23 & 4.75 & 1.16 & .04 & .02 & .42 & .59 & .13 & .23 & .25 & .13 & .24 & -.02 \\
\hline 11 & 4.48 & 1.71 & 4.01 & 1.39 & .03 & -.04 & .07 & -.08 & .91 & .81 & -.13 & .03 & .13 & .03 \\
\hline 12 & 4.91 & 1.84 & 4.84 & 1.36 & -.09 & .11 & .06 & .00 & .84 & .80 & .06 & -.13 & -.05 & -.13 \\
\hline 13 & 4.92 & 1.90 & 5.42 & 1.23 & .11 & -.06 & .16 & .12 & .77 & .72 & -.05 & .02 & -.09 & .05 \\
\hline 14 & 3.96 & 1.66 & 3.10 & 1.18 & .06 & -.10 & -.36 & -.18 & .75 & .44 & .03 & .03 & -.07 & .25 \\
\hline 15 & 5.81 & 1.04 & 5.16 & 1.12 & .03 & -.19 & -.11 & .25 & -.08 & -.03 & .94 & .76 & .01 & -.01 \\
\hline 16 & 5.61 & 1.40 & 5.23 & .99 & -.05 & .00 & .14 & .28 & -.00 & .07 & .89 & .70 & -.19 & -.06 \\
\hline 17 & 5.69 & 1.17 & 5.04 & 1.11 & .10 & .15 & -.12 & -.15 & .03 & -.04 & .66 & .70 & .33 & .01 \\
\hline 18 & 5.57 & 1.51 & 5.08 & .99 & .31 & .36 & -.15 & -.16 & .01 & -.08 & .51 & .48 & .33 & .20 \\
\hline 19 & 4.32 & 1.75 & 3.98 & 1.41 & -.11 & -.00 & .15 & .19 & .04 & -.09 & .13 & -.04 & .84 & .78 \\
\hline 20 & 3.86 & 1.95 & 5.19 & 1.18 & -.08 & -.11 & -.03 & -.15 & -.08 & .04 & -.05 & .14 & .91 & .75 \\
\hline 21 & 4.84 & 1.73 & 4.49 & 1.38 & .78 & .18 & .07 & .17 & .03 & .18 & -.36 & -.14 & .44 & .67 \\
\hline \multicolumn{3}{|c|}{ Eigenvalues } & & & 9.07 & 5.71 & 1.26 & 1.91 & 1.48 & 1.64 & 2.50 & 1.36 & 1.02 & 1.25 \\
\hline \multicolumn{3}{|c|}{$\%$ Variance explained } & & & 43.18 & 27.17 & 5.99 & 9.11 & 7.06 & 7.83 & 11.91 & 6.50 & 4.84 & 5.97 \\
\hline \multicolumn{5}{|c|}{ Cumulative $\%$ variance explained } & & & 49.17 & 36.28 & 56.23 & 44.11 & 68.13 & 50.61 & 72.97 & 56.58 \\
\hline
\end{tabular}

Bold figures indicate loadings greater than .4 


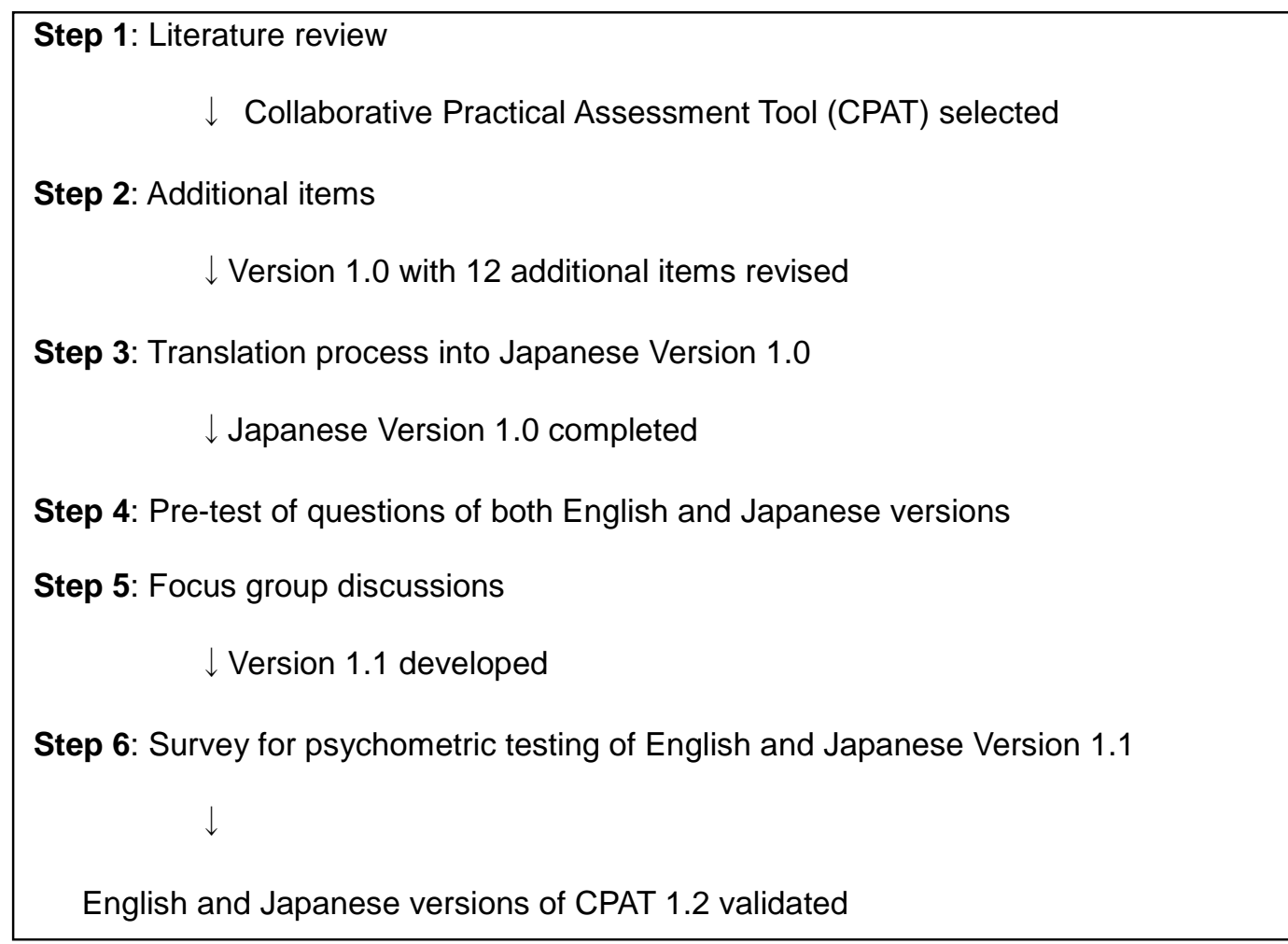

Figure 1: Flowchart outlining the sequence of methods in the development of both English and Japanese CPAT 1. 